\title{
Etiologies of Ischemic Stroke in Sub-Saharan Africa, Case of Benin
}

\author{
Mendinatou Agbetou $^{1 *}{ }^{(\mathbb{B}}$, Arlos Sowanou$^{2}$, Gérard Goudjinou2, Constant Adjien², \\ Dismand Houinato², Dieu donné Gnonlonfoun²
}

${ }^{1}$ Department of Neurology, Teaching Hospital, Parakou, Bénin

${ }^{2}$ Department of Neurology, Teaching Hospital, Cotonou, Bénin

Email: *mendiagbetou@yahoo.fr

How to cite this paper: Agbetou, M., Sowanou, A., Goudjinou, G., Adjien, C., Houinato, D. and Gnonlonfoun, D. (2020) Etiologies of Ischemic Stroke in Sub-Saharan Africa, Case of Benin. Neuroscience \& Medicine, 11, 100-107.

https://doi.org/10.4236/nm.2020.114012

Received: September 12, 2020

Accepted: November 23, 2020

Published: November 26, 2020

Copyright $\odot 2020$ by author(s) and Scientific Research Publishing Inc. This work is licensed under the Creative Commons Attribution International License (CC BY 4.0).

http://creativecommons.org/licenses/by/4.0/

\begin{abstract}
The purpose of our study was to investigate etiologies of ischemic stroke in the neurology university clinic of CNHU-HKM, Cotonou. Method: It was a cross-sectional, prospective and analytical study carried out from $1^{\text {st }}$ November 2014 to $31^{\text {st }}$ August 2015 in the neurology university clinic of CNHU-HKM. We included all patients with stroke whose ischemic nature was confirmed through brain CT scan or magnetic resonance imaging. Data analysis was conducted with Census and Survey Processing System (CSPRO). We carried out bivariate then multivariate analysis in identifying associated factors. Threshold value is estimated at $p<0.05$. Results: 104 ischemic stroke patients participated in the study, representing $59.4 \%$ of all types of stroke. Mean age was $61.9 \pm 12.3$ years [26 - 87 years] with 1.6 as sex ratio. Among vascular risk factors, hypertension accounted for $85.6 \%$ of stroke cases. $29.8 \%$ suffered from aphasia. Embolic heart diseases and atherosclerosis were predominant, in a proportion of $53 \%$ and $26 \%$ respectively. Atrial Fibrillation (AF) accounted for $82 \%$ of embolic heart diseases. Conclusion: Etiologic investigation of stroke is important and should be systematically carried out. This study enabled to corroborate atherosclerosis predominance in etiologic investigation of ischemic stroke. Patients' outcome could be improved by promptly managing the etiology through adoption of appropriate treatment.
\end{abstract}

\section{Keywords}

Ischemic Stroke, Etiologies, Benin, Africa

\section{Introduction}

Just as cancer and cardiovascular diseases, stroke is one of the top public health priorities, as the understanding of epidemiological data has contributed to a bet- 
ter awareness of the magnitude of this medical issue [1] [2]. It accounts for about $44.4 \%$ of admissions in the Neurology Department of Hubert Maga Koutougou National Teaching Hospital (CNHU-HKM) [3] and 32.9\% in the neurology department of Lomé Teaching Hospital in Togo [4]. It is the most common condition observed in patients admitted to accident and emergency department, especially in Benin [5]. This serious and recurrent medical issue ultimately leads to ischemic stroke in $80 \%$ of cases [6]. Given the poor technical facilities and financial difficulties faced by Sub-Saharan Africans, very few studies were conducted to investigate the etiology of ischemic stroke. Yet, ischemic stroke prognosis is considerably associated with etiological management [7] [8]. Thus, the purpose of this study is to identify the various etiologies of ischemic stroke in Benin hospital setting so as to reduce its mortality.

\section{Method}

\section{Population}

It was a prospective and descriptive study carried out from $1^{\text {st }}$ November 2014 to $31^{\text {st }}$ August 2015 . The study population was all patients followed in the neurology university clinic during the study period. Sample size was determined in accordance with Daniel Schwartz formula:

$$
n=\frac{Z \alpha^{2} p q}{i^{2}}
$$

$n=$ sample size, $p=44.4 \%$ stroke prevalence in neurology clinic of CNHU-HKM (3). $q=(1-p)=55.6 \%=0.56 . \alpha=5 \%$ hence $Z \alpha=1.96(z$-score refers to $\alpha$ risk $=5 \%) . i=10 \%$ (desired precision). The result obtained was $n=95$. However, 104 ischemic stroke patients have been included. During the study period, we systematically included up to the planned maximum number, all patients with stroke whose ischemic nature was confirmed by a brain CT scan or magnetic resonance imaging, and who provide informed consent. Cerebral venous thrombosis cases have been excluded.

Diagnosis criteria

Extra and intracranial atherosclerosis was diagnosed based on the following criteria: existence of risk factors for atherosclerosis (age, diabetes, hypertension, obesity, smoking ...), presence of atheromatous plaque corroborated with Doppler ultrasound of supra-aortic trunks. Stenosis was considered as significant when above $70 \%$.

Embolic heart diseases were diagnosed on the basis of cardiac diagnostic tests including:

- Arrhythmia (Atrial Fibrillation, Atrial Flutter) and myocardial infarction assessed through ECG and Holter

- Transthoracic echocardiography for the diagnosis of valvular heart disease (mitral valve stenosis, calcified aortic stenosis ...), hypertrophic cardiomyopathy, patent foramen ovale and atrial septal aneurysm (ASA)

Paraclinical tests $(\mathrm{CBC}$, hemoglobin electrophoresis, protein $\mathrm{S}$ assay, protein 
C assay) are established on the basis of hematological etiologies for diagnosis.

Infectious vasculitis is established when the syphilis and retroviral serology used for their diagnosis is positive and the other etiology-driven tests are normal.

Statistical analysis

Data collected were entered and analyzed through Census and Survey Processing System (CSPRO) version 6.1. Statistical Analysis Software (SAS) version 9.3 and Excel 2013 were used to produce various tables and graphs. Sample description was carried out in compliance with common statistics: Quantitative variables were expressed through mean values with their standard deviations, interval confidence estimated at $95 \%$.

\section{Results}

Over the study period, a total of 250 patients were admitted. Frequency of stroke was recorded 70\% (175/250). Ischemic stroke accounted for 59.4\% (104/175) of all types of stroke. Mean age of the 104 patients with ischemic stroke was $61.9 \pm$ 12.3 years [26 - 87 years] with 1.6 as sex ratio. Our study highlighted hypertension and obesity as predominant personal medical history, with respectively $85.6 \%$ and $39.4 \%$.

Systolic BP ranged from 80 to $240 \mathrm{mmHg}$ with $166.6( \pm 30.8) \mathrm{mmHg}$ as mean value. Diastolic BP was $95.5 \pm 20.7$, with 100 and $159 \mathrm{mmHg}$ as extreme values. All patients developed motor impairment. 29.8\% of our patients suffered from aphasia. Table 1 summarized socio-demographic and clinical characteristics.

Upon the biological tests carried out, $23.3 \%$ had high level of total cholesterol, and its mean was estimated at $1.9( \pm 0.526) \mathrm{g} / \mathrm{L}$, with extreme values ranging from $1.03-3.8 \mathrm{~g} / \mathrm{L} .26 .2 \%$ of the study population had high LDL cholesterol, with $1.3( \pm 0.5) \mathrm{g} / \mathrm{l}$ and $0.4-3.3 \mathrm{~g} / \mathrm{L}$ as mean value and extreme values respectively. Furthermore, hypertriglyceridemia was recorded in $23.8 \%$ of the patients. $30.6 \%$ of our study population had hyperuricemia, with $59.6( \pm 20.1) \mathrm{mg} / \mathrm{L}$ as mean value. Treponema-specific bacterium test was negative in all patients included in the study, however, two (02) patients representing $1.9 \%$ tested positive for HIV.

As regards paraclinical tests, 95 out of 104 patients performed electrocardiogram (ECG). It was abnormal in $15.8 \%$ of cases. Table 2 highlights the various ECG abnormalities.

Holter-ECG was performed in 79 patients. Some patients had normal ECG and abnormal Holter-ECG. $25.3 \%$ of the study population had abnormal Holter-ECG, hence the need of performing Holter-ECG in etiological investigation of ischemic stroke. Table 3 highlights patients' distribution according to Holter-ECG.

Doppler echocardiography was performed in 85 patients. It revealed abnormalities in $7.1 \%$ of patients, including $3.5 \%$ valvular heart disease, $2.3 \%$ ischemic heart disease and $1.2 \%$ atrial septal aneurysm and right ventricular apical aneurysm (Figure 1). 
Table 1. Socio-demographic and clinical characteristics of ischemic stroke.

\begin{tabular}{|c|c|c|}
\hline & Number (n) & Percentage (\%) \\
\hline \multicolumn{3}{|l|}{ Age } \\
\hline$<55 y$ & 32 & 30.8 \\
\hline$\geq 55 y$ & 72 & 69.2 \\
\hline \multicolumn{3}{|l|}{ Gender } \\
\hline Male & 64 & 61.5 \\
\hline Female & 40 & 38.5 \\
\hline \multicolumn{3}{|l|}{ Style of life } \\
\hline Alcoholism & 45 & 43.3 \\
\hline Tabagism & 9 & 8.7 \\
\hline Inactivity & 83 & 79.8 \\
\hline \multicolumn{3}{|l|}{ Occupation } \\
\hline Retirement & 44 & 42.3 \\
\hline Household & 23 & 22.1 \\
\hline Official & 25 & 24.1 \\
\hline Artisan & 12 & 11.5 \\
\hline \multicolumn{3}{|l|}{ Level of education } \\
\hline Illiterate & 11 & 10.8 \\
\hline Primary & 38 & 36.3 \\
\hline Secondary & 43 & 41.2 \\
\hline University & 12 & 11.7 \\
\hline \multicolumn{3}{|l|}{ Medical history } \\
\hline Hypertension & 89 & 85.5 \\
\hline Obesity & 41 & 39.4 \\
\hline Diabetes & 31 & 29.8 \\
\hline Stroke & 27 & 25.9 \\
\hline Cholesterol & 2 & 1.9 \\
\hline Arteritis obliterans of the lower limbs & 9 & 8.6 \\
\hline Hormonal contraception & 1 & 1 \\
\hline \multicolumn{3}{|l|}{ Motor deficiency } \\
\hline Paralysis & 60 & 57.5 \\
\hline Paresis & 44 & 42.5 \\
\hline Disorders of consciousness & & 19 \\
\hline \multicolumn{3}{|l|}{ Aphasia } \\
\hline Broca & 18 & 58 \\
\hline Wernicke & 2 & 6.5 \\
\hline Mixed & 11 & 35.5 \\
\hline
\end{tabular}


Table 2. Patients distribution according to the result of abnormal ECG.

\begin{tabular}{ccc}
\hline ECG result & Number (n) & Percentage (\%) \\
\hline Normal & 80 & 84.21 \\
Myocardial infarction & 2 & 2.11 \\
Arrhythmia (AF) ${ }^{*}$ & 13 & 13.68 \\
Total & 95 & 100 \\
\hline
\end{tabular}

* AF: Atrial Fibrillation.

Table 3. Patients distribution according to the result of the abnormal Holter-ECG.

\begin{tabular}{ccc}
\hline Results of Holter-ECG & Number (n) & Percentage (\%) \\
\hline Normal & 59 & 74.68 \\
Myocardial infarction & 2 & 2.53 \\
Arrhythmia (AF) & 18 & 22.79 \\
Total & 79 & 100 \\
\hline
\end{tabular}

* AF: Atrial Fibrillation.

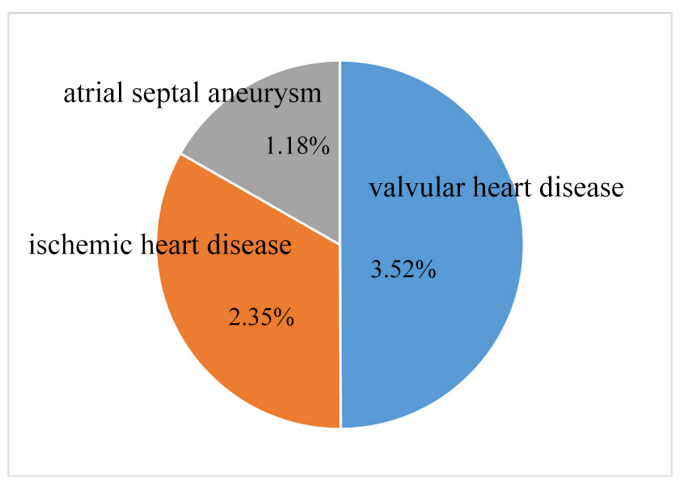

Figure 1. Abnormalities found on Doppler echocardiography.

Of the 104 patients included in the study, 85 performed Doppler ultrasound of supra-aortic trunks. Nonstenosing and stenosing atheromatous plaques were in a proportion of $95.6 \%$ and $4.4 \%$ respectively.

Atherosclerosis (53\%) was the leading etiology in our study population. Figure 2 highlights patients' distribution according to the etiology.

\section{Discussion}

The mean age of our patients was $61.9 \pm 12.3$ years [26 - 87 years], similar to the figure recorded by Gombert et al. in 2007 in Brazzaville [9]. As regards vascular risk factors, hypertension was present in $85.5 \%$ of patients followed by obesity in a proportion of $39.4 \%$. A study conducted in Mali highlighted similar results i.e. $61 \%$ hypertensive patients and $45.8 \%$ obese [10].

Hypertension is the most important modifiable risk factor for myocardial infarction in both sexes, regardless of age. It increases the risk of myocardial infarction by 4 , and $40 \%$ to $85 \%$ of patients with cerebral infarction are hypertensive [11]. The role of obesity as an independent risk factor for cerebral infarction 


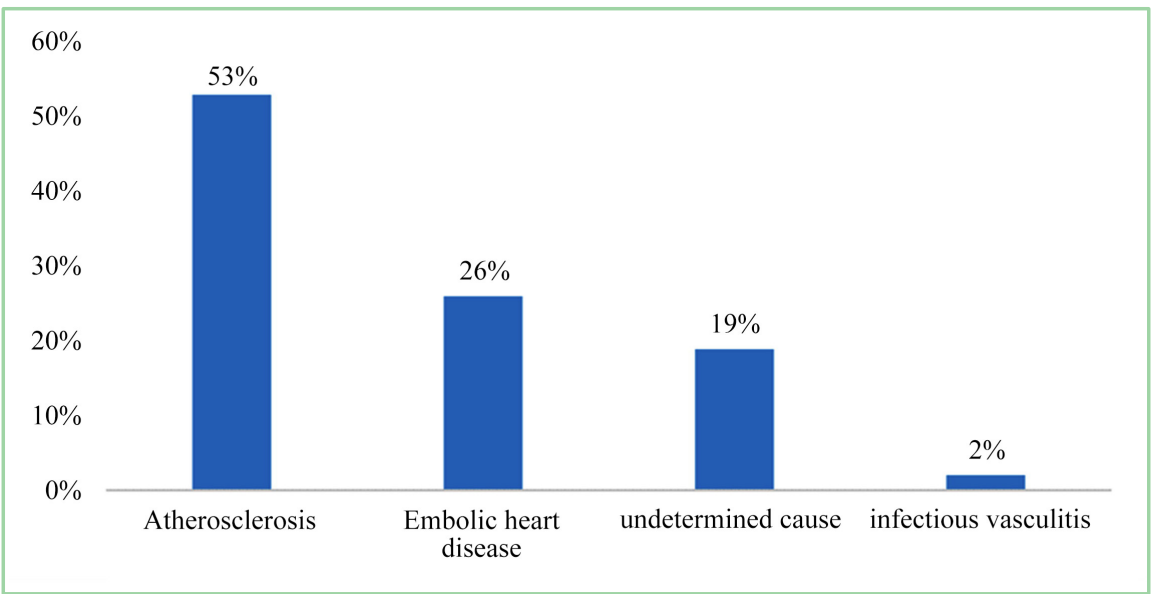

Figure 2. Etiology of ischemic stroke.

is demonstrated through a relative risk increased by a factor of 2 [12], exacerbated by risk factors such as hypertension, diabetes and hypercholesterolemia. Weight loss resulting in lowered blood pressure and remediation of cholesterol abnormalities, may reduce the risk of stroke, though this is yet to be established [13]. The mean value for systolic and diastolic blood pressure was respectively $166.6 \pm 30.8$ and $95.5 \pm 20.7$. Secondary prevention requires lowering this blood pressure, because according to Gorelick et al., $9 \mathrm{mmHg}$ drop in systolic blood pressure and $4 \mathrm{mmHg}$ diastolic blood pressure would reduce by $26 \%$ the risk of stroke recurrence [14]. Biologically, the presence of cholesterol was noted in 23.3\% of patients. This figure is higher than results of Tazi and all in Morocco [15] who recorded $10.9 \%$ hypercholesterolemia. This gap could be explained by the fact that consumption of non-vegetable oil is much higher in our country. It's known that lipid-lowering effect of statins is considerable in secondary stroke prevention, with a reduced risk from $19 \%$ to $32 \%$ [16]. As regards the etiology of ischemic stroke, atherosclerosis was in large proportion, followed by embolic heart disease and finally infectious vasculitis in a proportion of $53 \%$, $26 \%$ and $2 \%$ respectively. Nearly $19 \%$ of the etiology of ischemic stroke was unknown. Kolominsky-Rabas et al. reported similar results with $41.1 \%$ atherosclerosis, 30.2\% embolic disease, 39.3\% unknown etiology, and 2.1\% for other etiologies [17]. Other studies carried corroborate the fact that atherosclerosis is the most common etiology of ischemic stroke with respectively $51 \%, 62 \%$, and $41 \%$ [18] [19]. However, Tardy et al. [20] in Toulouse and Suissa et al. in Nice in 2009 in France recorded predominant cardioembolic etiology followed by atherosclerosis etiology. They reported respectively $53.6 \%$ and $16 \%$ then $41.5 \%$ and $28.2 \%$. Westernization of lifestyle in sub-Saharan Africa and increased vascular risk factors confer on atherosclerosis the leading position in ischemic stroke etiologies.

\section{Conclusion}

Etiologic investigation of stroke is important and should be systematically car- 
ried out. This study enabled to corroborate atherosclerosis predominance in etiologic research of ischemic stroke. Patients' outcome could be improved by promptly managing the etiology through adoption of appropriate treatment.

\section{Limitations of the Study}

This prospective descriptive study may have been tainted by information bias, particularly prevarication. Indeed, age was self-reported and, in an environment where the illiteracy rate is not negligible, subjects tend to under- or overestimate their age. Nevertheless, to limit this effect, whenever subjects were asked for their national identity card or voter's card or birth certificate, they were provided it if possible. We also found a selection bias related to inclusion criteria based on the completion of the brain scan. However, we are in an environment where not all patients have the financial means to perform this examination. In addition, the rate of indeterminate strokes could have been lower if all the tests involved in the etiological research were performed.

\section{Conflicts of Interest}

The authors declare no conflicts of interest regarding the publication of this paper.

\section{References}

[1] Feigin, V.L., Mensah, G.A., Norrving, B., Murray, C.J.L., Roth, G.A., Bahit, M.C., et al. (2015) Atlas of the Global Burden of Stroke (1990-2013): The GBD 2013 Study. Neuroepidemiology, 45, 230-236. https://doi.org/10.1159/000441106

[2] Feigin, V.L., Norrving, B. and Mensah, G.A. (2017) Global Burden of Stroke. Circulation Research, 120, 439-448. https://doi.org/10.1161/CIRCRESAHA.116.308413

[3] Gnonlonfoun, D., Adjien, C., Ossou-Nguiet, P., Mapoure, Y., Houinato, D. and Avode, D. (2013) La fréquence hospitalière des affections neurologiques au CNHU-HKM de Cotonou. Journal de la Société de Biologie Clinique, 18, 43-48.

[4] Balogou, A.A.K., Tossa, K.R., Kowu, A., Belo, M. and Grunitzky, K.E. (2004) Hospitalization Charges for Patients in the Neurology Department of Lomé Teaching Hospital. Sante, 14, 109-114.

[5] Cossi, M.-J., Gobron, C., Preux, P.-M., Niama, D., Chabriat, H. and Houinato, D. (2012) Stroke: Prevalence and Disability in Cotonou, Benin. Cerebrovascular Diseases, 33, 166-172. https://doi.org/10.1159/000334195

[6] Bejot, Y., Caillier, M., Rouaud, O., Benatru, I., Maugras, C., Osseby, G.-V., et al. (2007) Epidemiology of Strokes. Impact on the Treatment Decision. La Presse médicale, 36, 117-127. https://doi.org/10.1016/j.lpm.2006.11.006

[7] Al Kasab, S., Derdeyn, C.P., Guerrero, W.R., Limaye, K., Shaban, A. and Adams, H.P. (2018) Intracranial Large and Medium Artery Atherosclerotic Disease and Stroke. Journal of Stroke \& Cerebrovascular Diseases, 27, 1723-1732. https://doi.org/10.1016/j.jstrokecerebrovasdis.2018.02.050

[8] Kaddumukasa, M., Kayima, J., Nakibuuka, J., Blixen, C., Welter, E., Katabira, E., et al. (2017) Modifiable Lifestyle Risk Factors for Stroke among a High Risk Hypertensive Population in Greater Kampala, Uganda; a Cross-Sectional Study. BMC Re- 
search Notes, 10, 675. https://doi.org/10.1186/s13104-017-3009-7

[9] Gombert, T.R. and Ellenga, M.I.M. (2007) Facteurs de risques des accidents vasculaires cérébraux ischémiques au CHU de Brazaville. Médécine d afrique Noire, 54, 639-645.

[10] Damorou, F., Togbossi, E., Pessinaba, S., Klouvi, Y., Balogou, A., Belo, M., et al. (2008) Cerebral Vascular Accidents and Embolic Cardiovascular Diseases. Le Mali Medical, 23, 31-33.

[11] Denolle, T., Chamontin, B., Doll, G., Fauvel, J.-P., Girerd, X., Herpin, D., et al. (2016) Management of Resistant Hypertension: Expert Consensus Statement from the French Society of Hypertension, an Affiliate of the French Society of Cardiology. Journal of Human Hypertension, 30, 657-663. https://doi.org/10.1038/jhh.2015.122

[12] Mitchell, A.B., Cole, J.W., McArdle, P.F., Cheng, Y.-C., Ryan, K.A., Sparks, M.J., et al. (2015) Obesity Increases Risk of Ischemic Stroke in Young Adults. Stroke, 46, 1690-1692. https://doi.org/10.1161/STROKEAHA.115.008940

[13] Saeed, E., Ali, R., Jalal-ud-din, M., Saeed, A., Jadoon, R.J. and Moiz, M. (2015) Hypercholesterolemia in Patients of Ischemic Stroke. Journal of Ayub Medical College Abbottabad, 27, 637-639.

[14] Gorelick, P.B. and Aiyagari, V. (2013) The Management of Hypertension for an Acute Stroke: What Is the Blood Pressure Goal? Current Cardiology Reports, 15, 366. https://doi.org/10.1007/s11886-013-0366-2

[15] Tazi, M.A., Abir-Khalil, S., Chaouki, N., Cherqaoui, S., Lahmouz, F., Sraïri, J.E., et al. (2003) Prevalence of the Main Cardiovascular Risk Factors in Morocco: Results of a National Survey, 2000. Journal of Hypertension, 21, 897-903. https://doi.org/10.1097/00004872-200305000-00013

[16] AIM-HIGH (2011) The Role of Niacin in Raising High-Density Lipoprotein Cholesterol to Reduce Cardiovascular Events in Patients with Atherosclerotic Cardiovascular Disease and Optimally Treated Low-Density Lipoprotein Cholesterol: Baseline Characteristics of Study PARTICI. American Heart Journal, 161, 538-543. https://doi.org/10.1016/j.ahj.2010.12.007

[17] Kolominsky-Rabas, P.L., Weber, M., Gefeller, O., Neundoerfer, B. and Heuschmann, P.U. (2001) Epidemiology of Ischemic Stroke Subtypes According to TOAST Criteria: Incidence, Recurrence, and Long-Term Survival in Ischemic Stroke Subtypes: A Population-Based Study. Stroke, 32, 2735-2740. https://doi.org/10.1161/hs1201.100209

[18] Renna, R., Pilato, F., Profice, P., Della Marca, G., Broccolini, A., Morosetti, R., et al. (2014) Risk Factor and Etiology Analysis of Ischemic Stroke in Young Adult Patients. Journal of Stroke \& Cerebrovascular Diseases, 23, 221-227. https://doi.org/10.1016/j.jstrokecerebrovasdis.2013.10.008

[19] Zhang, Y.-N. and He, L. (2012) Risk Factors Study of Ischemic Stroke in Young Adults in Southwest China. Journal of Sichuan University. Medical Science Edition, 43, 553-557.

[20] Tardy, J., Albucher, J.F. and Pariente, J.C.F. (2007) Evaluation à 4ans de la filière urgences AVC de l'hôpital Purpan (Toulouse) et analyse de 69 patients consécutifs traités par rt-PA intra-veineux. Revue Neurologique, 163, 349-357.

https://doi.org/10.1016/S0035-3787(07)90407-5 